\title{
Prevalence of Substance Abuse Among Dormitory Students of Shahid Beheshti University of Medical Sciences, Tehran, Iran
}

\author{
Akbar Babaei Heydarabadi ${ }^{1}$; Ali Ramezankhani ${ }^{2}$; Hasan Barekati ${ }^{2}$; Marjan Vejdani ${ }^{3}$; \\ Keyvan Shariatinejad ${ }^{4}$; Rahman Panahi ${ }^{5}$; Seyed Hanan Kashfi ${ }^{6}$; Masoumeh Imanzad ${ }^{7, *}$ \\ ${ }^{1}$ Department of Public Health, School of Health, Ahvaz Jundishapur University of Medical Sciences, Ahvaz, IR Iran \\ ${ }_{3}^{2}$ Department of Public Health, School of Health, Shahid Beheshti University of Medical Sciences, Tehran, IR Iran \\ 3 Iranian Research Center on Healthy Aging, Sabzevar University of Medical Sciences, Sabzevar, IR Iran \\ ${ }^{4}$ School of Nursing and Midwifery, Mashhad University of Medical Sciences, Mashhad, IR Iran \\ 5 School of Nursing and Midwifery, Mashhad University of Medical Sciences, Mashhad, IR Iran

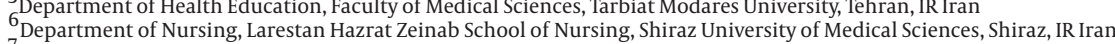 \\ ${ }_{7}$ Department of Nursing, Larestan Hazrat Zeinab School of Nursing, Shiraz University
Young Researchers Club, Shar-e-Qods Branch, Islamic Azad University, Tehran, IR Iran \\ ${ }^{*}$ Corresponding author: Masoumeh Imanzad, Young Researchers Club, Shar-e-Qods Branch, Islamic Azad University, Tehran, IR Iran. Tel: +98-2146896000, E-mail: \\ Imanzadmasoumeh@yahoo.com
}

Received: July 27, 2014; Revised: October 20, 2014; Accepted: October 25, 2014

Background: Adolescence is a risky period with high tendency towards drug abuse. Addressing the problem of drug abuse among students is essential.

Objectives: This study was carried out in 2013 with the purpose of investigating the prevalence of substance abuse among dormitory students of Shahid Beheshti University of Medical Sciences.

Patients and Methods: In this descriptive analytical study, which was carried out in 2013, a total of 604 students living at dormitories of Shahid Beheshti University of Medical Sciences were selected by random sampling method. A questionnaire designed by the researcher was used to collect the data. Data were analyzed using descriptive statistics and chi-square test.

Results: The prevalence of substance abuse among the students was $15.4 \%$. With respect to the types of the drug used by students, the highest frequencies belonged to smoking $4.47 \%$ and hookah with $42.9 \%$. Forty-eight percent of the students, who used drugs, started it for the first time when they were 18 years old or younger. About $58 \%$ of students used drugs for the first time in dormitories and parks. Students' meetings and parties with friends were frequent occasions for substance abuse (47.5\%).

Conclusions: Students are considered one of the most vulnerable groups of society. The students living in dormitories are more vulnerable to drug abuse due to the lack of parental supervision and the impact of peer pressure. Therefore, localization of acceptance at Universities in order to prevent cultural mixing of students and education programs for teaching life skills to students efficiently reduce their substance abuse.

Keywords: Prevalence; Drugs; Students

\section{Background}

Substance abuse has been one of the most serious human problems in recent years and is one of the complex phenomena undermining the foundation of human society. Preventing substance abuse requires application of multiple theories and techniques in various scientific fields (1-4). Substance abuse is a nonadaptive model of substance use, which leads to many problems and adverse outcomes. It has a series of cognitive, behavioral, and psychological symptoms (5). It is also one of the important social pathologies, which not only endangers the health of the individual and society, but also leads to mental and ethical decline (6-10).

Drug addiction is one of the major problems in developing countries (11-13). Since these countries have young populations, they are at greater risk of addiction. The youth are the most vulnerable age group who are at higher risk of drug addiction $(14,15)$. Because of its particular human and geographical conditions, our country has been faced with drug addiction (16). The most common age range of drug abusers in the world is 18 to 25 years (17). Currently, there are information from inside and outside the country that shows that substance abuse is increasing among young people and students (18-22). Like other young people, students are not away from this problem (23-25). The consumption of addictive drugs causes reduction in life span, incidents, aggressive sexual behaviors, unwanted pregnancy, suicide, aggression, crime, accident, and personality or psychological disorders $(26,27)$. Addiction causes various damages among students, including interruption in research and study process, increase in substance abuse among students, and further dissemination of the cul-

Copyright (C) 2015, Zahedan University of Medical Sciences. This is an open-access article distributed under the terms of the Creative Commons Attribution-NonCommercial 4.0 International License (http://creativecommons.org/licenses/by-nc/4.0/) which permits copy and redistribute the material just in noncommercial usages, provided the original work is properly cited. 
Babaei Heydarabadi A et al.

ture of substance abuse in the student community and the entire society who deem the educated class as a role model (18). In Iran, substance abuse is one of the important public health, treatment, social, and cultural issues, so that more than $90 \%$ of Iranian people expressed their concerns about substance abuse in the society. Statistics indicates that the prevalence rate of substance abuse was $2.65 \%$ among the Iranian population aged 15 to 64 years. The approximate number of addicts was estimated to be 1325000 (1). The studies show that the rate of drug addiction nearly doubles every 12 years in Iran and an $8 \%$ is added to the addicts' population annually (28). Persuading or pressure of friends, education and job stress, as well as curiosity are the most common reasons of drug abuse among general population (29). This tendency among young people living away from their families, including dormitories can be attributed to low and inadequate recreational facilities, being away from family, lack of emotional support, and other problems (30). Research shows that many Canadian youth use alcohol, tobacco, marijuana, and illegal substances (31, 32). Alcohol overuse is one of the risk behaviors that have harmful effects on health (33). In the United States, at least 1400 students die from alcohol-related unintentional accidents every year (34). The results of a study conducted in 2005 in our country showed that the prevalence rate of cigarette use was $15.3 \%$ and the average number of smoked cigarettes was $14.69 \%$ (35). In another study conducted in Shiraz in 2002, it was proved that $30.23 \%$ of young adults had used addictive drugs at least once and $23.86 \%$ were addicted to the following substances: $8.3 \%$ cigarette, $1 \%$ heroin, $0.3 \%$ morphine, $4.3 \%$ alcohol, $0.8 \%$ opium and its by-products, $0.3 \%$ LSD, $0.5 \%$ cocaine, $0.8 \%$ hashish, and $0.8 \%$ marijuana (36). Various studies have reported the prevalence of smoking among University students of Iran at the considerable amount of $10 \%$ (37). The results of a study on medical students at the University of Tehran in 2009-2010 academic year, showed that the highest rate of addiction belonged to hookah (25.7\%) followed by cigarettes (18\%), alcohol (11.8\%), and opium (2.3\%) (38). Now, experts believe that epidemiological investigations should be the first step in designing preventive programs. Several studies have been carried out with the purpose of identifying types of substances used and the problems associated with them, estimating age of initiation, identifying vulnerable groups, assessing environmental and background factors as a measure of effectiveness of prevention programs, providing statistical indicators and norms for policy making and investigating the influence of peer groups and other influential groups (39-41). Since students constitute an important part of the society and the number of students is increasing at Universities, smoking must be carefully considered in this group. Accordingly, determining prevalence of smoking in this group is essential for planning and selecting suitable intervention strategies (37).

\section{Objectives}

The purpose of this study was to assess the prevalence of substance abuse among dormitory students of Shahid Beheshti University of Medical Sciences in 2013.

\section{Patients and Methods}

In this cross-sectional study, 604 students (299 males and 365 females) with an age range of 18 to 45 years living in the dormitories for more than 6 months were selected via random sampling. Data were analyzed using a questionnaire developed by the researcher, including demographic information (7 items), behavioral questions (17 items), and substance abuse table ( 8 items with 7 parts). The questionnaire was developed based on Dehghani et al. study (16), literature review, and expert opinions obtained from related professors to approve its reliability and validity. The content validity and reliability of the questionnaire was confirmed based on comments of 10 faculty members with Cronbach $\alpha$ of 0.84 . After obtaining the necessary instructions, interviewers went to the student dormitories and administered the questionnaire to collect self- report data. To reduce any potential bias due to the sensitivity of the issue, the participants were ensured that questionnaires will be collected in sealed boxes. Data were analyzed using SPSS 16 via descriptive statistics, and chi-square, and Fisher exact tests were performed.

\section{Results}

In this study, a sample of 604 students was selected aged 18 to 45 years living in dormitories of Shahid Beheshti University of Medical Sciences. About $62.9 \%$ of the students (380 students) were female and 37.1\% $(n=224)$ were male. With respect to degree of education, $40.6 \%$ ( $n$ $=245)$ studied at the undergraduate level, $8.8 \%(n=53)$ at graduate level, $45.9 \%(n=277)$ at MD level and 4.8\% $(n=29)$ at PhD level. Average length of stay in the dormitory was $18.38 \pm 27.28$ months. The prevalence rate of substance abuse among students was $15.4 \%$. This rate was $43.4 \%$ for males and $4.2 \%$ for females. Regarding types of substance abused by the students, the highest frequency belonged to cigarette (47.4\%) followed by hookah (42.9\%). About half $(48 \%)$ of the students who used substance started it when they were 18 years old or younger. Most of the students who smoked cigarette (77.8\%) started smoking seriously when aged 18 to 22 years. More than half (51\%) of the students using substances reported that they started that before entering college (Table 1).

With respect to the first place of substance abuse, $25.4 \%$ of students reported dormitories, $25.4 \%$ park, $21.9 \%$ parents' homes, and $10.5 \%$ their friends' home. Current substance abuse places were dormitory (35.7\%) and friend's house (20.5\%) (Table 2). First substance abuse status included $52.1 \%$ at meeting with friends, $24.5 \%$ when depressed, 7.4\% when happy, and 5.3\% at birthday parties. Current substance abuse status included $47.5 \%$ at meetings with friends (Table 3 ). 
Babaei Heydarabadi A et al.

Table 1. Frequency Based on First Substance Use, Age at First Substance Abuse, Age at First Smoking of Cigarettes and Time When Starting Substance Abuse ${ }^{\text {a }}$

\begin{tabular}{lc}
\hline Variable & Frequency $(\%)$ \\
\hline First substance use & \\
\hline Cigarettes & $63(47.4)$ \\
\hline Hookah & $57(42.9)$ \\
\hline Opium & $3(2.3)$ \\
\hline Heroin & $2(1.5)$ \\
\hline Alcohol & $7(5.3)$ \\
\hline Psychotropic pills & $1(0.8)$ \\
\hline Age at first substance abuse, $\mathbf{y}$ & \\
\hline less than 18 & $59(48)$ \\
\hline 18 to 22 & $58(46.3)$ \\
\hline More than 22 & $6(5.7)$ \\
\hline Age at first smoking of cigarettes, y & \\
less than 18 & $10(18.5)$ \\
\hline 18 to 22 & $42(77.8)$ \\
\hline More than 22 & $2(3.7)$ \\
\hline Time when starting substance abuse & \\
\hline Before entering college & $49(51)$ \\
\hline After entering college & $47(49)$ \\
\hline a Data are presented as No. (\%).
\end{tabular}

Table 2. Frequency Based on the First and Current Substance Abuse Place $^{\mathrm{a}}$

\begin{tabular}{lc}
\hline Variable & Frequency (\%) \\
\hline First substance abuse place & \\
\hline Parents' home & $25(21.9)$ \\
\hline Friends' home & $12(10.5)$ \\
\hline Dormitories & $29(25.4)$ \\
\hline Park & $29(25.4)$ \\
\hline Other & $19(16.7)$ \\
\hline Current substance abuse place & \\
\hline Parents' home & $6(5.4)$ \\
\hline Friends' home & $23(20.5)$ \\
\hline Dormitories & $40(35.7)$ \\
\hline Park & $21(18.8)$ \\
\hline Other (campus, city, travel) & $22(19.6)$ \\
\hline a Data are presented as No.(\%). \\
\hline
\end{tabular}

Table 3. Frequency Based on First and Current Substance Abuse Status ${ }^{\text {a }}$

\begin{tabular}{lc}
\hline Variable & Frequency (\%) \\
\hline First substance abuse status & \\
\hline Meeting with friends & $49(52.1)$ \\
\hline When depressed & $5(5.3)$ \\
\hline When happy & $23(24.5)$ \\
\hline At birthday parties & $7(7.4)$ \\
\hline Other & $10(10.6)$ \\
\hline Current substance abuse status & \\
\hline Meeting with friends & $29(47.5)$ \\
\hline At birthday parties & $6(9.8)$ \\
\hline When depressed & $13(21.3)$ \\
\hline When happy & $13(21.3)$ \\
\hline a Data are presented as No. (\%).
\end{tabular}

Table 4. Frequency Based on Type of Substance, Number of Cigarettes Smoked Per Day, Type of Cigarettes Smoked, and Place of Substance Purchase ${ }^{\text {a }}$

\begin{tabular}{|lc}
\hline Variable & Frequency $(\%)$ \\
\hline Type of substance & \\
\hline Cigarettes & $63(30.7)$ \\
\hline Hookah & $60(29.3)$ \\
\hline Pipe & $16(7.8)$ \\
\hline Opium & $9(4.4)$ \\
\hline Heroin & $4(2)$ \\
\hline Alcohol & $19(9.3)$ \\
\hline Hashish & $25(12.2)$ \\
\hline Methamphetamine & $2(1)$ \\
\hline Psychotropic pills & $5(2.4)$ \\
\hline Crack & $2(1)$ \\
\hline $\begin{array}{l}\text { Number of cigarettes } \\
\text { smoked per day }\end{array}$ & \\
\hline Less than 5 & $12(30)$ \\
\hline 5 to 10 & $14(35)$ \\
\hline More than 10 & $14(35)$ \\
\hline Type of cigarette & \\
\hline foreign & $28(33.3)$ \\
\hline domestic & $6(7.1)$ \\
\hline Both & $40(47.6)$ \\
\hline Chase & \\
\hline Around substance pur- & $2(49.6)$ \\
\hline Campus & \\
\hline Data are presented as No.(\%). & \\
\hline
\end{tabular}

Hookah and cigarette use had the highest prevalence among substances used by students. Among those who responded to the question regarding the number of cigarettes smoked per day, $70 \%$ smoked more than 5 cigarettes a day, while about $30 \%$ of students who were cigarette smokers did not answer the question. With regard to the type of cigarette smoked, most students (81.6\%) smoked foreign cigarettes. In addition, about $15 \%$ of students cigarette smokers did not answer this question. Among the students that abused substance, $(47.6 \%)$ reported the city as the place where they bought substances (Table 4 ).

\section{Discussion}

This study investigated the prevalence of substance abuse among students at dormitories of Shahid Beheshti University of Medical Sciences in 2013. The prevalence rate of substance abuse was $34.4 \%$, among male students and $4.2 \%$ among female students. Several studies conducted at the Universities of Medical Sciences across the country re- 
Babaei Heydarabadi A et al.

ported substance abuse between $20 \%$ to over $40 \%(16,42)$. A study of medical students in India reported prevalence rates of substance abuse from $32.5 \%$ to $81.2 \%$ (43). This difference can be related to cultural reasons, participants' beliefs, and differences in methodology and instruments used to gather the data. In this study, the most widely used substance was cigarette (47.4\%) followed by Hookah (42.9\%). In the study by Ahmadi et al. the most widely used substance was cigarette (25.3\%) (44). In Moemen Nasab et al. (45), the most widely used substances were Hookah (29.7\%) and cigarette (25.1\%). Results of study by Rezakhani Moghadam et al. (18) indicated a higher prevalence for cigarette (22.7\%) and hookah (26.6\%). Taremian et al. stated that $34 \%$ of students had a history of hookah, $24 \%$ smoking, and $17 \%$ alcohol abuse (39). Hookah smoking is common in many countries, especially in the Middle East and Africa. Studies about the dangers of hookah smoking indicated its relationship with increased risk of oral, stomach, esophagus, and lungs cancer, reduced respiratory function and fertility (46). Based on various studies carried out at universities in industrialized countries, alcohol is the first and the most widely used substance among students, which is used by almost $44 \%$ of students (1). Researchers in the other study on substance abuse in 1997 found that $82.4 \%$ of participants had a history of alcohol use (18). Percentage of alcohol use in domestic studies is significantly lower than that of foreign studies, which can be due to religious beliefs and the unlawfulness of alcohol use in Islam. In this study, most students who were cigarette smokers (77.8\%) started smoking seriously when aged 18 to 22 years. It can be purported to peer pressure and its effects on high risk behaviors (18). In many countries, the age of vulnerability to drug addiction has been between 20 and 34 years (5). In the study by Karimy et al. (47) more than $56 \%$ of smokers had at least one experience of smoking before the age of 15 , which is consistent with the results of many studies related to smoking such as the study conducted in Ukraine and Warren (48) and the other study in 76 countries around the world (49). Several studies show that onset of smoking is significantly associated with adolescence (50). Arvanitidou et al. reported age as one of the risk factors associated with adolescents' cigarette smoking and demonstrated that with increasing age, the risk of smoking increases (51). In this study, about half of the students who abused substance did so for the first time when aged less than 18 years. Serajzadeh and Feizi reported 17.6 years as the average onset age for substance abuse. Given the fact that the first use among a significant number of university students has been reported before entering college, developing plans to reduce substance demand at high school and before seems to be necessary (52). In this study, $70 \%$ of cigarette smokers smoked more than 5 cigarettes a day. In the study conducted by Zareipour et al.(53) entitled "Factors influencing smoking behavior among male students in Tehran University of Medical Sciences based on BASNEF model", 60\% of students reported over 5 cigarettes as their number of cigarettes smoked daily. Because cigarettes are sold in packs and individually, access is easier with lower prices (53). Studies showed that even smoking a cigarette can cause heart palpitations and increase in blood pressure (46). Therefore, enhancing the students' participation in extracurricular activities (educational, cultural, recreational, and sport) and providing programs for prevention and control of substance abuse by Student Advice Centers and other relevant institutions can be useful. Nonhomogeneous distribution of students in dormitories (with respect to major and level) and lack of honesty in students' responses due to social sensitivity of the issue (despite ensuring anonymity by using sealed boxes) were among the restrictions of this study. Students are one of the most vulnerable groups in the society. Students living in dormitories are more vulnerable to substance abuse due to lack of parental control and the impact of peer pressure. Therefore, localized acceptance of students into the universities in order to maintain students' contact with their families and to help them benefit from the family supportive environment alongside programs for teaching life skills to them can reduce their substance abuse.

\section{Acknowledgements}

This study is the result of a research project approved and registered by number 1762 . The researcher hereby expresses warm appreciation to Research and Technology Deputy as well as Culture and Student Deputy of Shahid Beheshti University of Medical Sciences and the students who participated in the study.

\section{Authors' Contributions}

Akbar Babaei Heydarabadi, Ali Ramezankhani, Masoumeh Imanzad: study design, article writing; Rahman Panahi, Marjan Vejdani: data collection; Keyvan Shariatinejad, Hasan Barekati: data analysis; Masoumeh Imanzad, Seyed Hanan Kashfi, Akbar Babaei Heydarabadi: Critical revision of the manuscript for important intellectual content.

\section{Funding/Support}

This study was funded and supported by Deputy of Research and Culture and Student Deputy of Shahid Beheshti University of Medical Sciences (Grant No: 1762).

\section{References}

1. Sarrami H, Ghorbami M, Taghavi M. The Survey Two Decades of Prevalence Studies among Iran University Students. J Res Educ Drug Control Headquarters . 2013;7(27):9-36.

2. Nakhaee N, Ziaaddini H, Karimzadeh A. Epidemiologic Study on Drug Abuse among First and Second Grade High School Students in Kerman. Addict Health. 2009;1(1):31-6.

3. Mohammadpoorasl A, Ghahramanloo AA, Allahverdipour H, Augner C. Substance abuse in relation to religiosity and familial support in Iranian college students. Asian J Psychiatr. 2014;9:41-4. 


\section{Babaei Heydarabadi A et al.}

4. Wenthur CJ, Cross BS, Vernon VP, Shelly JL, Harth BN, Lienhoop $\mathrm{AD}$, et al. Opinions and experiences of Indiana pharmacists and student pharmacists: the need for addiction and substance abuse education in the United States. Res Social Adm Pharm. 2013;9(1):90-100.

5. Madadi A, Nogani F. [The textbook of Addiction and substance abuse]. Iran: 2005.

6. Ziaaddini H, Qahestani A, Moin Vaziri M. Comparing Symptoms of Withdrawal, Rapid Detoxi-fication and Detoxification with Clonidine in Drug Dependent Patients. Addict Health. 2009;1(2):63-8

7. Verdipour H, Heydarnia A, Kazemnejad A, Shafiee F, Falah A, Mirzaee A. Survey of substance abuse in students and integrating self-control factor in the model EPPM. J Med Scie Yazd. 2005;13(1):21-13.

8. Cook S, Turner NE, Ballon B, Paglia-Boak A, Murray R, Adlaf EM, et al. Problem Gambling Among Ontario Students: Associations with Substance Abuse, Mental Health Problems, Suicide Attempts, and Delinquent Behaviours. J Gambl Stud. 2014.

9. Aristeiguieta CA. Substance abuse, mental illness, and medical students: the role of the Americans with Disabilities Act. JAMA. 1998;279(1):80.

10. Chakroun N, Doron J, Swendsen J. [Substance use, affective problems and personality traits: test of two association models]. Encephale. 2004;30(6):564-9.

11. Mohanty S, Tripathy R, Palo SK, Jena D. Socioeconomic, demographic study on substance abuse among students of professional college in a southern town, Berhampur of Odisha state (India). J Forensic Leg Med. 2013;20(8):1057-62.

12. Ziaaddini H, Sharifi A, Nakhaee N, Ziaaddini A. The Prevalence of at Least One-Time Substance Abuse among Kerman Pre-university Male Students. Addict Health. 2010;2(3-4):103-10.

13. Al-Haqwi AI. Perception among medical students in Riyadh, Saudi Arabia, regarding alcohol and substance abuse in the community: a cross-sectional survey. Subst Abuse Treat Prev Policy. 2010;5:2.

14. Goreishi A, Shajari Z. Substance Abuse among Students of Zanjan's Universities (Iran): A Knot of Today's Society. Addict Health. 2013;5(1-2):66-72.

15. Mohammadpoorasl A, Nedjat S, Fakhari A, Yazdani K, Foroushani AR, Fotouhi A. Substance abuse in high school students in association with socio-demographic variables in northwest of iran. Iran J Public Health. 2012;41(12):40-6.

16. Dehghani K, Zare A, Dehghani H, Sedghi H, Movahhedpour Z. [Prevalence and factors associated with drug abuse among students of Yazd University of Medical Sciences]. J Shaheed Sadoughi Univ Med Sci. 2010;18(3):164-9.

17. McCabe SE, Morales M, Cranford JA, Delva J, McPherson MD, Boyd CI. Race/ethnicity and gender differences in drug use and abuse among college students. J Ethn Subst Abuse. 2007;6(2):75-95.

18. Rezakhani Moghadam H, Shojaeizadeh D, Lashgarara B, Safari H, Savadpour M, Sohbatzadeh R. [Comparison of substance abuse and its causes among students of tehran university of medical sciences and university of Tehran]. J Health Syst Res. 2012;8(7):1300-10.

19. Momtazi S, Rawson R. Substance abuse among Iranian high school students. Curr Opin Psychiatry. 2010;23(3):221-6.

20. Singh H, Maharaj HD, Shipp M. Pattern of substance abuse among secondary school students in Trinidad and Tobago. Public Health. 1991;105(6):435-41.

21. Wechsler H, Lee JE, Rigotti NA. Cigarette use by college students in smoke-free housing: results of a national study. Am J Prev Med. 2001;20(3):202-7.

22. Clark CM. Substance abuse among nursing students. Establishing a comprehensive policy and procedure for faculty intervention. Nurse Educ. 1999;24(2):16-9.

23. Parvizy S, Nikbahkt A, Pournaghash Tehrani S, Shahrokhi S Adolescents' perspectives on addiction: qualitative study. Nurs Health Sci. 2005;7(3):192-8.

24. Lewis TF, Mobley AK. Substance abuse and dependency risk: the role of peer perceptions, marijuana involvement, and attitudes toward substance use among college students. I Drug Educ 2010;40(3):299-314

25. Seshadri S. Substance abuse among medical students and doctors: a call for action. Natl Med J India. 2008;21(2):57-9.

26. Soresi S, Catalano F, Spatafora M, Bonsignore MR, Bellia V. Light smoking and dependence symptoms in high-school students. Respir Med. 2005;99(8):996-1003.

27. Ziaaddini $\mathrm{H}$, Nasirian M, Amiri R. Personality disorder diagnosis in substance-dependent women in Iran: Relationship to childhood maltreatment. Iran J Psychiatry. 2009;4(2):52-5.

28. Samouei R, Sohrabi A, Yarmohammadian MH. Why some previous drug abuse preventive programs had low effectiveness? Med Arch. 2013;67(1):68-72.

29. Shafiq M, Shah Z, Saleem A, Siddiqi MT, Shaikh KS, Salahuddin FF, et al. Perceptions of Pakistani medical students about drugs and alcohol: a questionnaire-based survey. Subst Abuse Treat Prev Policy. 2006;1:31.

30. Foroutani M, Rezaeian M. [ knowledge and drug abuse among university students in the town of Larestan]. Iran J Nurs. 2004;18(43):22-9.

31. Hammond D, Ahmed R, Yang WS, Brukhalter R, Leatherdale S. Illicit substance use among Canadian youth: trends between 2002 and 2008. Can J Public Health. 2011;102(1):7-12.

32. Leatherdale ST, Ahmed R. Alcohol, marijuana, and tobacco use among Canadian youth: do we need more multi-substance prevention programming? J Prim Prev. 2010;31(3):99-108.

33. Zadarko-Domaradzka M, Zadarko E, Barabasz Z, Sobolewski M [Alcohol use and health-risk behaviours among academic students in Podkarpackie]. Przegl Lek. 2013;70(8):546-50.

34. Cox RG, Zhang L, Johnson WD, Bender DR. Academic performance and substance use: findings from a state survey of public high school students. J Sch Health. 2007;77(3):109-15.

35. Sharifirad G, Charkazi A, Mansourian M. [Categorizing and analysis of smoking based on transtheoretical models among male students of Isfahan Medical Sciences and Isfahan University]. $J$ Health. 2011;2(1):56-65.

36. Ahmadi J, Hasani M. Prevalence of substance use among Iranian high school students. Addict Behav. 2003;28(2):375-9.

37. Haghdoost AA, Moosazadeh M. The prevalence of cigarette smoking among students of Iran's universities: A systematic review and meta-analysis. J Res Med Sci. 2013;18(8):717-25.

38. Sarami H, Ghorbani M, Minoei M. Survey of four decades of addiction prevalence researches in Iran. Q JRes Addict. 2013;7(26):29-52.

39. Taremian F, Bolhari J, Peiravi H, Tabatabaii M. [The prevalence of substance use among students in Tehran. Iranian Journal of Psychiatry and Clinical Psychology]. Iran J Psychiatry Clin Psychol. 2008;113(4):335-42.

40. Coleman EA, Honeycutt G, Ogden B, McMillan DE, O'Sullivan PS Light $\mathrm{K}$, et al. Assessing substance abuse among health care students and the efficacy of educational interventions. J Prof Nurs. 1997;13(1):28-37.

41. Davis TC, George RB, Long S, Bates W, Morris G, Anderson J. Sophomore medical students as substance abuse prevention teachers. J La State Med Soc. 1994;146(6):275-8.

42. Siam S. [Prevalence of drug abuse among male students in different universities in Rasht-2005]. Tabibe Shargh. 2006;8(4):279-84.

43. Kumar P, Basu D. Substance abuse by medical students and doctors. J Indian Med Assoc. 2000;98(8):447-52.

44. Ahmadi J, Maharlooy N, Alishahi M. Substance abuse: prevalence in a sample of nursing students. JClin Nurs. 2004;13(1):60-4.

45. Moemen Nasab M, Najafi S, Kaveh M, Ahmadpoor F. [Revalence of risk behaviour in students of academy centers of Khoramabad city in 2005]. Yafteh. 2006;8(2)

46. Taraghijah S, Hamdiyeh M, Yaghoubi N. [Predictors of smoking shisha in public universities. Journal of Research In Medical Sciences]. J Research In Medical Sciences. 2010

47. Karimy M, Niknami S, Heidarnia A, Hajizadeh E. [Assessment of Knowledge, Health Belief and Patterns of Cigarette Smoking Among Adolescents]. J Fasa Univ Med Sci. 2007;3(1):86-92.

48. Abedini S, Kamalzadehtakhti H, Sadeghifar E, Shahrakivahed A. [The survey of cigarette smoking situation in Bandar Abbas Medical students]. J Hormozgan Univ Med Sci. 2007;11(4):297-302. 


\section{Babaei Heydarabadi A et al.}

49. Warren CW, Lea V, Lee J, Jones NR, Asma S, McKenna M. Change in tobacco use among 13-15 year olds between 1999 and 2008: findings from the Global Youth Tobacco Survey. Glob Health Promot. 2009;16(2 Suppl):38-90.

50. Villanti A, Boulay M, Juon HS. Peer, parent and media influences on adolescent smoking by developmental stage. Addict Behav. 2011;36(1-2):133-6.

51. Arvanitidou M, Tirodimos I, Kyriakidis I, Tsinaslanidou Z, Sereto- poulos D. Decreasing prevalence of alcohol consumption among greek adolescents. Am J Drug Alcohol Abuse. 2007;33(3):411-7.

52. Serajzadeh H, Feizi I. [Alcohol and drug use among university students in Iran,2003-2004]. Soc WelfQ. 2007;6(25)

53. Zareipour M, Sadeghi R, Tabatabaei S, Seyedi S. [Effective factors on smoking based on BASNEF model in male students in Tehran medical sciences university in 2009]. J Urmia Nurs Midwifery Facu. 2011;9(1):24-9. 